Revista Eletrônica do Mestrado em Educação Ambiental

Programa de Pós-Graduação em Educação Ambienta1

\title{
Concepções de munícipes da cidade de Rio Claro sobre a arborização urbana
}

Éllen da Silva Garcia ${ }^{1}$

Dalva Maria Bianchini Bonotto ${ }^{2}$

Resumo: Com a intensa urbanização e crescimento das cidades, o tema arborização urbana se torna um tema importante dentro das questões ambientais discutidas e praticadas atualmente. Visto que nem sempre a população reconhece a importância das árvores, este trabalho teve a finalidade de investigar as concepções de munícipes da cidade de Rio Claro-SP sobre a arborização urbana, tentando analisar os significados do tema para essa população. Para atingir esse objetivo, usou-se a abordagem qualitativa, com entrevistas semiestruturadas; levando em consideração, além das respostas obtidas, as circunstâncias e o ambiente ao qual o entrevistado está inserido. A maioria dos entrevistados, aparentemente, reconhece a importância da arborização urbana; embora, muitas vezes, de forma utilitarista e antropocêntrica. Perspectiva que a educação ambiental pode ajudar a ser superada para que o reconhecimento das árvores seja ampliado, envolvendo, além dos conhecimentos, valores e ações mais apropriadas.

Palavras-chave: árvores, pesquisa qualitativa, educação ambiental.

\section{Concepciones de algunos residentes de la ciudad de Río Claro sobre la arborización urbana}

Resúmen: Con la intensa urbanización y crecimiento de las ciudades, se hace importante el tema de arborización urbana, haciendo parte de las cuestiones ambientales discutidas actualmente. Dado que no siempre la población comprende esa necesidad, no reconociendo los árboles como importantes, este trabajo tuvo la finalidad de investigar las concepciones de algunos residentes de la ciudad de Río Claro sobre la arborización urbana, intentando analizar los significados del tema para esa población. Para alcanzar ese objetivo, se utilizó el abordaje cualitativo, con entrevistas semi estructuradas, tomando en consideración, además de las respuestas obtenidas, las circunstancias y el ambiente al cual el entrevistado está inserto. La mayoría de los entrevistados, aparentemente, reconoce la importancia de la arborización urbana, aunque a menudo, de forma utilitarista y antropocéntrica. Perspectiva que la educación ambiental puede ayudar a ser superada

\footnotetext{
1 Graduada em Ciências Biológicas, Universidade Estadual Paulista - UNESP - Rio Claro- São Paulo. E-mail: ellen_silva.garcia@hotmail.com

${ }^{2}$ Professora Adjunta, Departamento de Educação do Instituto de Biociências da UNESP, campus de Rio Claro. E-mail: dalvambb@rc.unesp.br
}

Rev. Eletrônica Mestr. Educ. Ambient. Rio Grande, v. 34, n. 3, p. 112-129, set./dez. 2017. 
para que el reconocimiento de los árboles sea ampliado, ofreciendo, además de los conocimientos, valores y acciones más apropiados.

Palabras clave: árboles, investigación cualitativa, educación ambiental.

\title{
Population concepts about the urban afforestation in the Rio Claro city
}

\begin{abstract}
The intense urbanization and growth of big cities has become the urban afforestation an important subject within the environmental issues. This research purposes an investigation of Rio Claro citizens opinion about the subject since the population usually refuses to recognize the importance of the trees. Qualitative approach with semi-structured interviews was used to achieve this goal, takin into account the circumstances and the environment where the interviewee was inserted. Most respondents apparently recognize the importance of urban forestation; though often utilitarian and anthropocentric. It's expected that environmental education can provide the recognition of trees, involving a positive attitude about environment.
\end{abstract}

Keywords: trees, qualitative research, environmental education.

\section{INTRODUÇÃO}

A crise ambiental se tornou uma questão importante para a sociedade desde as últimas décadas do século XX. Buscando compreender a causa dos problemas ambientais, diversos autores têm apontado para vários fatores vindos da "concepção de mundo derivada da ciência mecanicista" (LAYRARGUES, 2004, p.38), como a construção de um modelo de racionalidade separando rigorosamente o sujeito cognoscitivo e o objeto do conhecimento e nossa sociedade capitalista, em cuja racionalidade cabe ao ser humano o domínio da natureza. A partir disso, se consolida nossa sociedade uma visão dicotomizada, como bem aponta Layrargues (2004):

Dialeticamente falando, para construirmos um novo patamar societário e de existência integrada às demais espécies vivas e em comunhão entre nós, precisamos superar as formas de expropriação que propiciam a dicotomia sociedade-natureza. (p. 79).

Até a Revolução Industrial, no começo de século XIX, não havia preocupação com a questão ambiental, mas após esse período, com a crescente urbanização e pelos fatores citados anteriormente, se intensificaram problemas ambientais como desmatamentos, queimadas, poluição e extração de recursos naturais para além da capacidade de restauração. Paralelamente a eles, a desigualdade e a exclusão social. Nesse sentido, reconhecemos que há um problema ao mesmo tempo social e ambiental, denominado de socioambiental, gerado pelo lucro de poucos em detrimento do esforço de muitos e/ 'uso', por poucos, dos bens ambientais de todos.

Dentre todos esses problemas, esse trabalho voltou-se para o tema da arborização

Rev. Eletrônica Mestr. Educ. Ambient. Rio Grande, v. 34, n. 3, p. 112-129, set./dez. 2017. 
urbana. Uma discussão atual importante, pois, na medida em que continua o crescimento urbano, dá-se o desmatamento para aumento da área construída das cidades. Para enfrentar esse problema, é preciso pensar em como manter e aumentar o contingente de árvores nas cidades para a minimização dos problemas urbanos.

Reconhece-se que um caminho que pode colaborar no enfrentamento desses transtornos é a Educação Ambiental (EA). Esta pode servir para trazer maior consciência à população sobre a importância da nossa moradia e convivência em sociedade. Considerando que os recursos que retiramos da natureza em prol das construções e modernização tecnológica podem acabar.

De acordo com Carvalho (2008), há necessidade de se estar atento à má distribuição e finitude dos recursos naturais, e também de se envolver o cidadão em ações ambientais apropriadas. Como a participação em grupos civis e movimentos organizados, "como esfera plural de decisões comuns que afetam o interesse público. Seja pela via dos movimentos nomeadamente ecológicos, seja pela via das lutas sociais pelo acesso público aos bens ambientais" (BRASIL, 2008, p.14).

Entretanto, há variação quanto ao entendimento do que seja a EA. Muitas vezes ela é apresentada como uma proposta de discussão para pensarmos a natureza sem a introdução do homem como parte dela, sob uma perspectiva conservacionista (LAYRARGUES, 2004). Nesse caso, a principal ideia é a de preservar o verde das matas, de replantar o que retiramos, de reintroduzir e/ou preservar a biodiversidade das comunidades de animais e plantas (CARVALHO, 1999), mas, sem muito aprofundamento nas questões de relacionamento entre nós, humanos, com os ambientes nos quais estamos inseridos: o natural, que é o não modificado; e o urbano, que é a natureza transformada pelo homem.

A EA, de acordo com Narcizo (2009), não pode ocorrer a partir de atividades pontuais, mas de uma forma mais ampla, que exige uma contínua reflexão e apropriação dos valores que remetem a ela. Normalmente, essas atividades são trabalhadas com temas; como reciclagem do lixo, preservação do verde e da água, todos de modo pontual. No entanto, segundo a autora, a "Educação Ambiental na escola deve ser um processo de permanente aprendizagem, que valoriza as diversas formas de conhecimento e colabore para a formação de cidadãos com consciência local e uma visão do planeta" (NARCISO, 2009, p.99). A EA, deveria estar de fato inserida no currículo escolar, constituindo uma boa oportunidade de desenvolver um trabalho que permita aos alunos se inserir nas problemáticas ambientais e sociais como sujeitos que se reconheçam causadores e também 
solucionadores dos desequilíbrios antrópicos. "Existem muitas dificuldades que limitam a inserção da EA na escola, dentre elas o currículo rigidamente disciplinar e a falta de suporte teórico e metodológico para o exercício da transversalidade.”. (SANTOS, SANTOS, 2016, p. 377).

Em vista da questão da arborização urbana, com o surgimento da urbanização e inerentemente seus problemas (ilhas de calor, inversão térmica, enchentes, mau trânsito, poluição do solo, das águas, do ar, dentre outros), a sociedade precisa se desdobrar para buscar formas de enfrentamento para, pelo menos, minimizar esses transtornos presentes na vida urbana, principalmente, por trazerem prejuízos à saúde, desarmonia à convivência na cidade, desequilíbrio ecológico e social. Mas será que a população pensa dessa forma?

Para Sarti (2009), a arborização urbana são os elementos vegetais de porte arbóreo dentro da cidade, as árvores plantadas nas calçadas; entretanto não integram o sistema de áreas verdes. Para o autor, a área verde engloba as praças, os jardins públicos e os parques urbanos. Para Moura (2010), a arborização urbana também são os elementos vegetais de porte arbóreo plantados em calçadas e, também não integram o sistema de áreas verdes. Mas, para este trabalho considerou-se as áreas verdes parte da arborização urbana, devido ao método utilizado das ortografias para identificar a porcentagem de copa de árvore em cada bairro, considerando todas as árvores do município: as que estão plantadas nas calçadas e as que fazem parte das áreas verdes.

Uma cidade bem arborizada traz uma série de benefícios se for planejada junto com o crescimento da malha urbana, como por exemplo: frescor, sombra, amortecimento da força das águas das chuvas e posterior filtração, embelezamento do local trazendo harmonia, atração de animais que buscam alimento e abrigo, aumentando a biodiversidade do local. Evitam alguns problemas urbanos citados anteriormente como ilhas de calor, inversão térmica, enchentes e poluição. Além de evitar o desequilíbrio ecológico que trazem consigo pragas e outros desajustes que possam prejudicar os recursos naturais, os animais e as plantas, ultrapassando o pensamento utilitarista e antropocêntrico.

Numa experiência como estagiária do setor de meio ambiente de uma cidade do interior paulista, Rio Claro, a autora pôde observar a partir das solicitações corte/poda de árvores para a "Secretaria Municipal de Planejamento, Desenvolvimento e Meio Ambiente" (SEPLADEMA); responsável pela autorização do serviço, que parece haver uma tendência dos munícipes da cidade em perceber as árvores mais como um problema do que uma necessidade. Os mesmos justificam o pedido de corte de árvores por diversos motivos: prejudicarem a fiação da rede elétrica, entupir calhas e bueiros, pela sujeira que 
fazem no quintal de suas residências, além de servirem como ponto de uso de drogas e como esconderijo para bandidos. Mas, até que ponto as árvores "sujam" quintais e calçadas? Até que ponto a presença de árvores está relacionada com a presença de bandidos? E até que ponto a retirada das árvores "resolve" esse problema?

Monico (2001) verificou em seu trabalho feito com dois grupos de moradores da cidade de Piracicaba- SP, que os inconvenientes trazidos pelas árvores são a sujeira provocada pela queda das folhas e flores, a aglomeração provocada por pessoas e carros na árvore na frente do imóvel e, acidentes e estragos pela queda da árvore. No trabalho de Cadorin (2013), a sujeira também apareceu dentro das principais desvantagens da arborização, citado 28 vezes por entrevistados de 5 bairros diferentes em Pato Branco - PR. Ficou atrás apenas da desvantagem de danificar a calçada, citado 35 vezes. Mas, como a autora diz: "as folhas, flores e frutos que caem das árvores fazem parte de um ciclo natural que não pode ser modificado ou interrompido" (CADORIN, 2013, p. 85). O mesmo se encontra em Moura (2010), quando o autor verificou que 19\% dos seus entrevistados, no centro de Teresina - PI, consideraram como principal problema causado pelas árvores a sujeira nas ruas e praças provocada pela queda de folhas e galhos. Além disso, o autor afirma que:

Para muitas pessoas, nos dias atuais, as praças são vistas como espaços públicos abandonados, da mendicância, do uso de drogas e da prostituição. Sendo assim, uma grande parcela da população da cidade fica praticamente sem espaço público livre para o desenvolvimento de diversas atividades relacionadas ao lazer, o encontro, o comércio e o descanso em horas de ócio. Faz-se necessário a criação e manutenção desses espaços para a melhoria da qualidade de vida da população. (MOURA, 2010, p. 35)

Considerando essas pesquisas, buscou-se nesse trabalho, investigar a questão na cidade de Rio Claro, sendo a autora estagiária na Diretoria de Meio Ambiente, dentro da SEPLADEMA. Neste período, surgiram algumas indagações que funcionaram como as principais motivações para o desenvolvimento deste trabalho, dentre elas: os munícipes dessa cidade reconheceriam a importância das árvores para a cidade? O que pensariam sobre o tema da arborização urbana? Essas questões conduziram para uma investigação em que se buscou identificar as concepções da população sobre esse tema, que poderiam, posteriormente, subsidiar programas de Educação Ambiental (EA) voltados a esse público.

Voltando-se às concepções, Valentin (2005, p. 97), para quem "uma concepção envolve saberes acumulados e vai sendo reconstituída e reelaborada de acordo com os 
acontecimentos, com as mensagens recebidas, com as relações estabelecidas e com o contexto vivido". Para Thompson (1992 apud VALENTIN, 2005, p. 97), as "concepções podem ser definidas como estruturas mentais (conscientes ou inconscientes) compostas por crenças (beliefs), conceitos, significados, regras, imagens mentais e preferências”.

Segundo Cadorin (2013), a tentativa de entender questões mais abrangentes como o significado da vegetação para populações urbanas e, a relação de convívio do homem com a natureza em ambientes que são altamente artificiais, torna-se um desafio. E acrescenta-se que esse entendimento é essencial para se planejar atividades educativas voltadas às necessidades detectadas, a fim de realizar trabalhos que estimulem a valorização dos espaços arborizados no meio urbano.

\section{OBJETIVOS E PROCEDIMENTOS DE PESQUISA}

A partir das considerações expostas, esse trabalho teve por finalidade investigar as concepções de munícipes da cidade de Rio Claro, ou seja, seus conhecimentos, ideias, opiniões, crenças e atitudes sobre a arborização urbana. Buscou-se, pois, identificá-las e analisá-las tentando descobrir seus significados, procurando, a partir delas, identificar possíveis causas; ou fatores que influenciam e levam a aceitação ou não da presença de árvores na cidade, assim como detectar aspectos que podem favorecer ou desfavorecer a realização e a manutenção da arborização urbana. Considera-se que esse tipo de trabalho poderá servir de subsídio para práticas educativas voltadas a esse tema, seja em espaços escolares ou não escolares.

Este trabalho parte da abordagem qualitativa que, de acordo com Ludke e André (1986), determina ser quase impossível entender o comportamento humano sem tentar entender o quadro referencial dentro do qual os indivíduos interpretam seus pensamentos, sentimentos e ações. Nessa perspectiva, o pesquisador deve tentar encontrar meios para compreender o significado manifesto e latente dos comportamentos dos indivíduos, ao mesmo tempo em que procura manter sua visão objetiva do fenômeno. A investigação se dá pelo contato direto do pesquisador com o ambiente e/ou situação a ser investigada, não sendo possível "estabelecer uma separação nítida e asséptica entre o pesquisador e o que ele estuda e também os resultados do que ele estuda" (LUDKE e ANDRE, 1986, p.5).

Preocupou-se mais com o processo do que com seu produto devido à atenção especial aos significados que os entrevistados dão à questão. Assim, preocupou-se em ouvir atentamente as colocações dos entrevistados (argumentos, lembranças, etc.), assim com suas reações (de estranhamento, demonstração de sentimentos) diante das questões 
formuladas, para buscar compreender esse processo de construção de significados em relação à arborização urbana.

A coleta de dados foi feita através de entrevistas que seguiram o modelo semiestruturado, que "se desenrola a partir de um esquema básico, porém não aplicado rigidamente, permitindo que o entrevistador faça as necessárias adaptações” (LUDKE E ANDRÉ, 1986, p.34).

Entrevistou-se munícipes de Rio Claro em diferentes situações, que poderiam influenciar a percepção da importância - ou prejuízos - da presença das árvores na vida dos moradores da cidade:

1- Morador de bairro pouco arborizado;

2- Morador de bairro bem arborizado;

3- Munícipes solicitantes de corte.

A cidade de Rio Claro tem uma população estimada de 186.253 habitantes em 2010 (IBGE, 2010), sendo considerada uma cidade de médio porte do interior paulista. Ela possui duas áreas verdes de maior porte, a Floresta Estadual "Edmundo Navarro de Andrade" (FEENA) e o Lago Azul.

Para a pesquisa, foram classificados e identificados bairros pouco e bem arborizados pelo levantamento de dados da porcentagem de copa de árvore retirada de 56 ortografias. A partir delas, se obteve uma tabela dos dados a partir das imagens. Foi considerado bairro bem arborizado aquele que apresentou maior porcentagem de copa de árvore e, bairro pouco arborizado aquele que apresentou a menor porcentagem de copa de árvore. Neste processo, incluem-se as árvores presentes na calçada, áreas verdes e áreas livres (de construção). Esse dado tornou-se importante porque será levado em consideração se a densidade de indivíduos arbóreos presentes no bairro do entrevistado poderá ser considerada um parâmetro significativo para as considerações coletadas nas entrevistas.

A análise dos dados se deu através de um processo indutivo, analisando-se o conteúdo das respostas às perguntas formuladas (LUDKE e ANDRÉ, 1986), a partir de leituras sucessivas. Não houve preocupação em generalizar as respostas como se representassem as concepções de todos os munícipes de Rio Claro, sendo essa mais um dos aspectos que caracteriza nossa pesquisa dentro da abordagem qualitativa. Nesta pesquisa, 
foram entrevistados ao todo 20 munícipes $^{3}$. As entrevistas foram realizadas a partir das seguintes questões básicas:

I- O local onde você mora com relação às árvores: como é? Você gosta dele?

II- Em sua infância, como era (m) o (s) local (is) em que você morou?

III- Você algum dia já plantou uma árvore e/ou outro tipo de planta? Se sim, conte como foi essa experiência.

IV- Você algum dia já teve que cortar uma árvore? Se sim, conte como foi essa experiência.

V- Aprendemos na escola que as árvores, como todas as plantas, são seres vivos. Você saberia dizer por que elas podem ser consideradas seres vivos? E você consegue perceber que elas são seres vivos, assim como os animais são seres vivos?

VI- Qual a sua opinião sobre as árvores nas cidades? E na cidade de Rio Claro? (elas têm alguma utilidade?)

As questões foram formuladas com o intuito de esclarecer algumas suposições levantadas a partir das leituras das justificativas expostas nos "Processos de Solicitação de Poda/Retirada de Árvores", encaminhadas para a Prefeitura da cidade. Assim foram consideradas as seguintes ideias:

1. O local de infância seria o mais querido, assim quem passa a maior parte dela em sítio ou fazenda tem maior ligação com a natureza.

2. Geralmente, quem solicita corte de árvore teria menos ligação com ela. E, provavelmente, nunca teria plantado uma.

3. Quem mora em bairro bem arborizado, apreciaria mais a natureza comparado com o grupo "morador de bairro pouco arborizado" e, dos "solicitantes de corte".

4. Quem planta uma árvore não teria "coragem" de cortar uma e, quem corta uma árvore não teria vontade de plantar.

\section{RESULTADOS E DISCUSSÃO GERAL}

Foi possível entrevistar 07 munícipes de Rio Claro moradores dos bairros Arco Íris e Floridiana, bairros pouco arborizados, (5\% de copa de árvore); 07 do bairro Vila Paulista,

\footnotetext{
${ }^{3}$ Essa pesquisa foi encaminhada ao Comitê de Ética em pesquisa do IB- UNESP/Rio Claro tendo sido aprovada.
} 
bem arborizado, (43,2\% de copa de árvore) e; 06 solicitantes de corte para a Prefeitura dos bairros: Arco Íris e Floridiana (5\%), Wenzel (10\%), Vila Indaiá (5,5\%), Vila Alemã (8,6\%) e Mãe Preta (entre 29\%-34\%).

Todos assinaram e receberam cópia do Termo de Consentimento Livre e Esclarecido (TCLE) exigido pelo Comitê de Ética em pesquisa, o qual deu parecer favorável a essa pesquisa.

Os dados e análises serão apresentados de acordo com as suposições previamente levantadas.

Suposição 1: O local de infância seria o mais querido, assim quem passa a maior parte dela em sítio ou fazenda teria maior ligação com a natureza.

Os munícipes solicitantes de corte foram os que mais relacionaram a infância com boas experiências com as árvores, o que nos chamou a atenção. $\mathrm{O}$ grupo do bairro pouco arborizado (Arco Íris/ Floridiana) não comentou nem experiências boas, nem ruins. E apenas um entrevistado declarou não gostar de árvores no grupo do bairro bem arborizado (Vila Paulista), como mostra a figura 1.

Figura 1: Respostas sobre a infância correlacionadas com árvores por grupo e total.

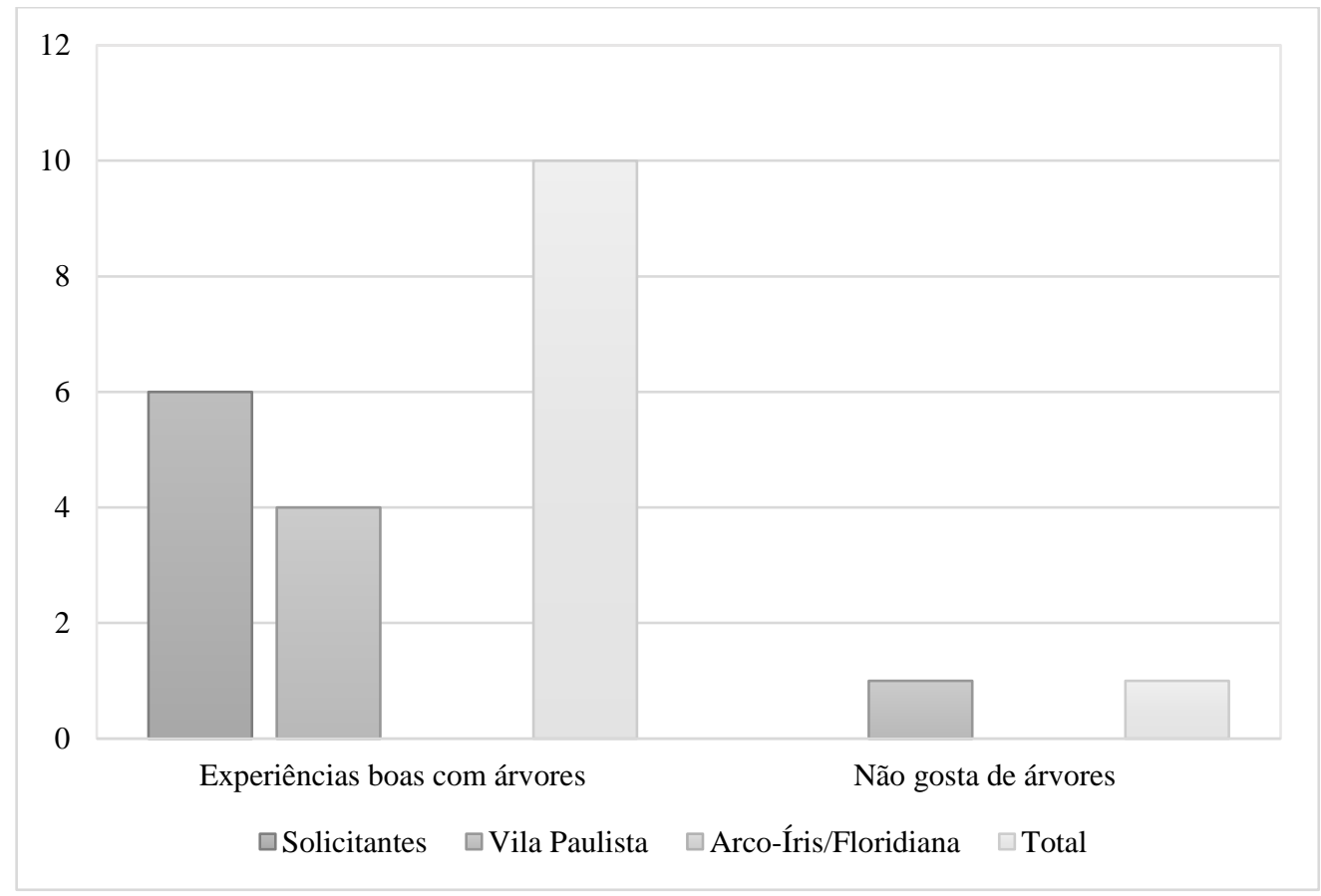

O local de maior vivência na infância pelos munícipes, (se viveu em sítio, fazenda, cidade do interior ou metrópole) pode ser fator relevante para determinar se a pessoa se

Rev. Eletrônica Mestr. Educ. Ambient. Rio Grande, v. 34, n. 3, p. 112-129, set./dez. 2017. 
tornaria um apreciador da natureza. Dois entrevistados do grupo dos solicitantes de corte que, apesar de terem vivido a maior parte da infância na cidade São Paulo (metrópole com predomínio de construções), demonstraram contemplar a natureza pois comentaram lembranças sobre as áreas bem arborizadas, como o Parque Ibirapuera. E na maioria dos casos, o local da infância foi comentado como o mais querido.

Suposição 2: Geralmente, quem solicita corte de árvore teria menos ligação com ela. E, provavelmente, nunca teria plantado uma.

Percebe-se que os grupos apresentaram números muito próximos de entrevistados que já plantaram alguma árvore ao longo da vida. Dos 7 entrevistados do bairro pouco arborizado (Arco Íris/Floridiana), 6 já plantaram uma árvore e apenas 1 cortou. Dos 7 do bairro bem arborizado (Vila Paulista), 6 já plantaram e 2 já cortaram e; dos 6 solicitantes de corte, todos já plantaram e 2 já cortaram.

Além disso, uma moradora do grupo dos solicitantes de corte, solicitou o corte de árvores na calçada devido à insistência dos vizinhos. Inicialmente, ela não concordava com o corte, mas como gerou uma situação de conflito, para evitar o mau relacionamento, acabou concordando. Destacamos aqui o fato que, durante a entrevista, a moradora ficava emocionada ao discorrer sobre outros cortes realizados por outrem em seu quintal por reclamações de vizinhos, visto que não tinha coragem dela mesma realizar e corte. Além disso, indicou que já tinha plantado duas árvores, uma para homenagear o nascimento de um filho e outra em memória a um animal de estimação.

O morador do grupo que solicitou o corte por terem invadido a sua casa pela árvore, e uma moradora do bairro bem arborizado, aparentemente, são os que plantaram árvores em maior quantidade.

Suposição 3: Quem mora em bairro bem arborizado apreciaria mais a natureza comparado com o grupo de bairro pouco arborizado e dos solicitantes de corte.

Os dados indicaram que o grupo que mora em bairro bem arborizado demonstrou mais intimidade com o meio natural (não urbanizado), tendo apresentado nas entrevistas um maior número de experiências boas envolvendo as árvores, além de que, a média de duração das entrevistas foi maior do que as dos outros grupos. Segue-se a ele, o grupo dos solicitantes de corte, demonstrando maior contato com a natureza. $\mathrm{O}$ grupo do bairro pouco arborizado apresentou a menor média de duração de entrevista. Muitos não sabiam ou não tinham o que dizer em relação a algumas perguntas apresentadas (como por exemplo, as duas pessoas que não souberam responder por que a árvore é um ser vivo na figura 2), e outros não introduziam referências à natureza ao falarem do bairro ou local de infância.

Rev. Eletrônica Mestr. Educ. Ambient. Rio Grande, v. 34, n. 3, p. 112-129, set./dez. 2017. 
Suposição 4: Quem planta uma árvore não teria coragem de cortar uma e quem corta uma árvore não teria vontade de plantar.

Alguns solicitantes demonstraram não ter coragem de propriamente cortar uma árvore, enquanto outros, sim. Um morador que já cortou árvores poderia ter cortado outra, que ele próprio plantou em sua casa para construir um portão, mas conseguiu realizar a construção sem a necessidade de cortar a árvore. Os moradores do bairro bem arborizado foram enfáticos ao dizer que nunca cortariam, manifestando expressões e palavras como se fossem matar um ser vivo. "Graças a Deus não". "Jamais. Nem cortaria se precisasse".

\section{ASPECTOS QUE SE DESTACARAM NAS ENTREVISTAS}

Diante do conjunto das respostas e da análise que efetuamos, podemos apresentar um conjunto de aspectos que emergiram desse trabalho e que consideramos importantes para trabalhos envolvendo a arborização urbana e a educação ambiental voltada a esse tema. Na figura 2, observamos os aspectos que emergiram nas entrevistas quando perguntado por que a árvore é um ser vivo.

Figura 2: Aspectos que se destacaram mais nas respostas sobre árvores e arborização urbana por grupo e total.

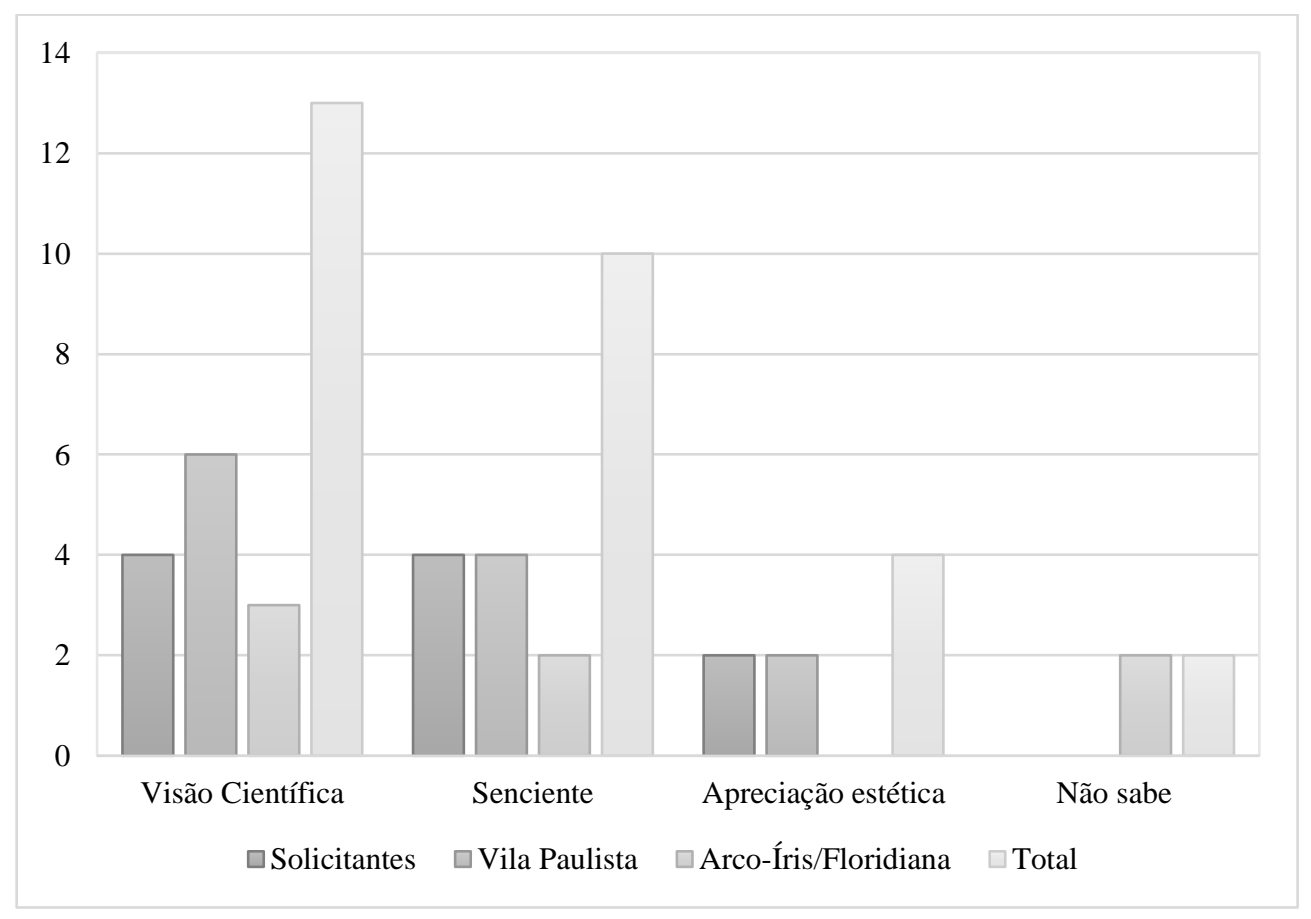

Em primeiro lugar, verificou-se o quanto os conhecimentos aparecem nas respostas dos entrevistados, informações que costumam ser ensinadas na escola. No entanto, no que

Rev. Eletrônica Mestr. Educ. Ambient. Rio Grande, v. 34, n. 3, p. 112-129, set./dez. 2017. 
se refere à apreciação estética, outro aspecto que costuma ser considerado importante para a Educação Ambiental, foi pouco citada (quatro vezes). O grupo do bairro pouco arborizado (Arco Iris/ Floridiana) não apresentou nenhuma citação referindo-se à questão da apreciação de árvores durante as entrevistas.

Em segundo lugar, se mostraram significativas as referências às árvores que foram comparadas aos animais, como seres que têm sentimentos e capacidade de sentirem dor, contrapondo-se ao o conhecimento científico propriamente dito, o qual não considera as plantas seres sencientes.

Por isto e por outros dados analisados, infere-se que não há um total desafeto dos munícipes com relação às árvores. Mesmo assim, seria importante que essa relação pudesse ser trabalhada nas escolas e junto à comunidade, visto que envolve desde o simples despertar do ato de gostar até uma valoração mais significativa, de querer que o objeto apreciado esteja presente para sua contemplação. Isso levaria a uma maior valorização da arborização urbana, caminho a partir do qual os valores construídos dentro de cada um sobre a natureza podem ser revelados e pautar nossas práticas de forma mais contundente.

Ao perguntar se no bairro havia poucas ou muitas árvores, ou ainda, se estaria satisfatória a quantidade das mesmas, a maioria respondeu que havia poucas (figura 3), e também na nossa pesquisa, a maioria declarou que gostaria que houvesse mais árvores. Não é possível avaliar o quanto essa resposta foi sincera ou foi apresentada para agradar a entrevistadora ou por ser considerada como uma resposta adequada.

Figura 3: Opinião dos munícipes sobre a quantidade de árvores por grupo e total.

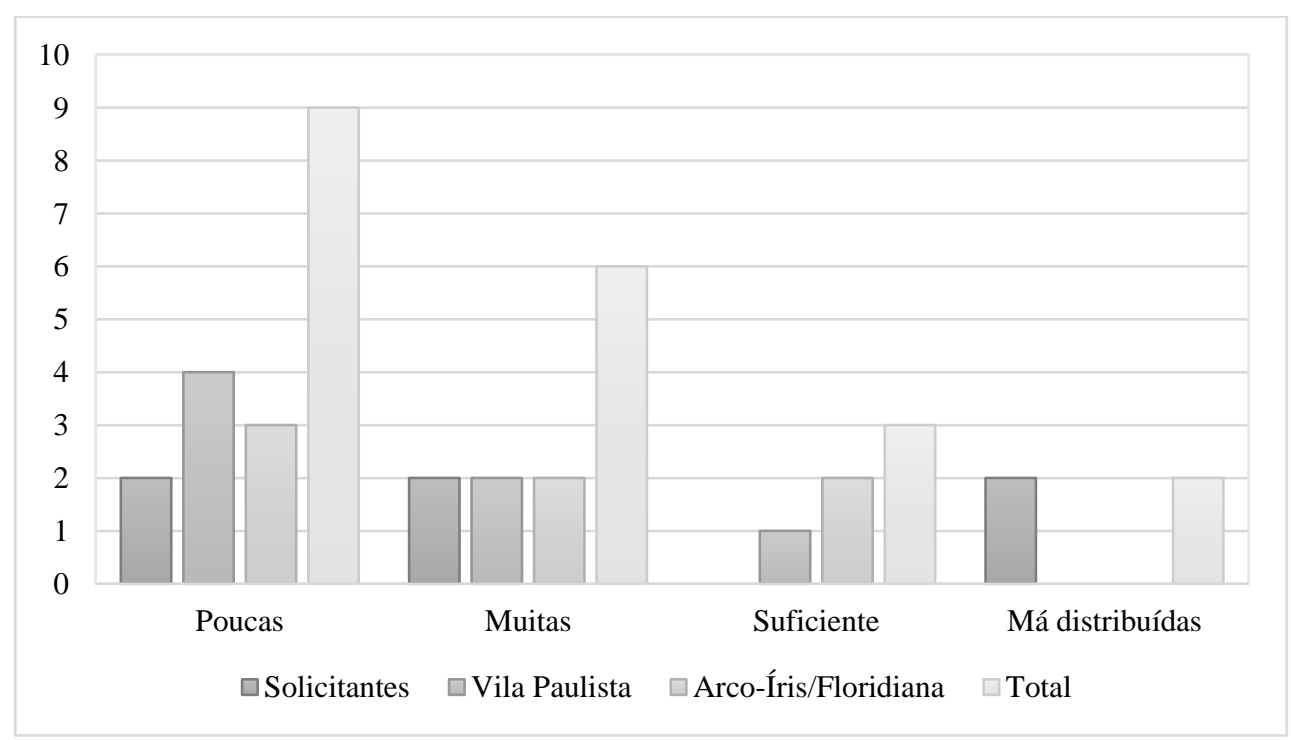

Rev. Eletrônica Mestr. Educ. Ambient. Rio Grande, v. 34, n. 3, p. 112-129, set./dez. 2017. 
Dois moradores, sendo um do bairro bem arborizado (Vila Paulista) e um do grupo dos solicitantes de corte, comentaram que as construções é que estão atrapalhando as árvores, com destaque à rede elétrica. Dos seis entrevistados do bairro pouco arborizado (Arco Íris/Floridiana), cinco disseram que a árvore não atrapalha, em nada: "A plantação não atrapalha nada, só ajuda a população”, declarou um deles.

Quantificando o número das palavras que aparecem nas respostas de cada munícipe em todas as perguntas, foram elaborados gráficos que explanam os motivos dos moradores gostarem do bairro (figura 4). Sobre os conhecimentos dos benefícios (figura 5) e prejuízos (figura 6) que as árvores podem trazer ao ambiente urbanizado.

Figura 4: Motivos citados os quais o entrevistado gosta do local onde mora por grupo e total.

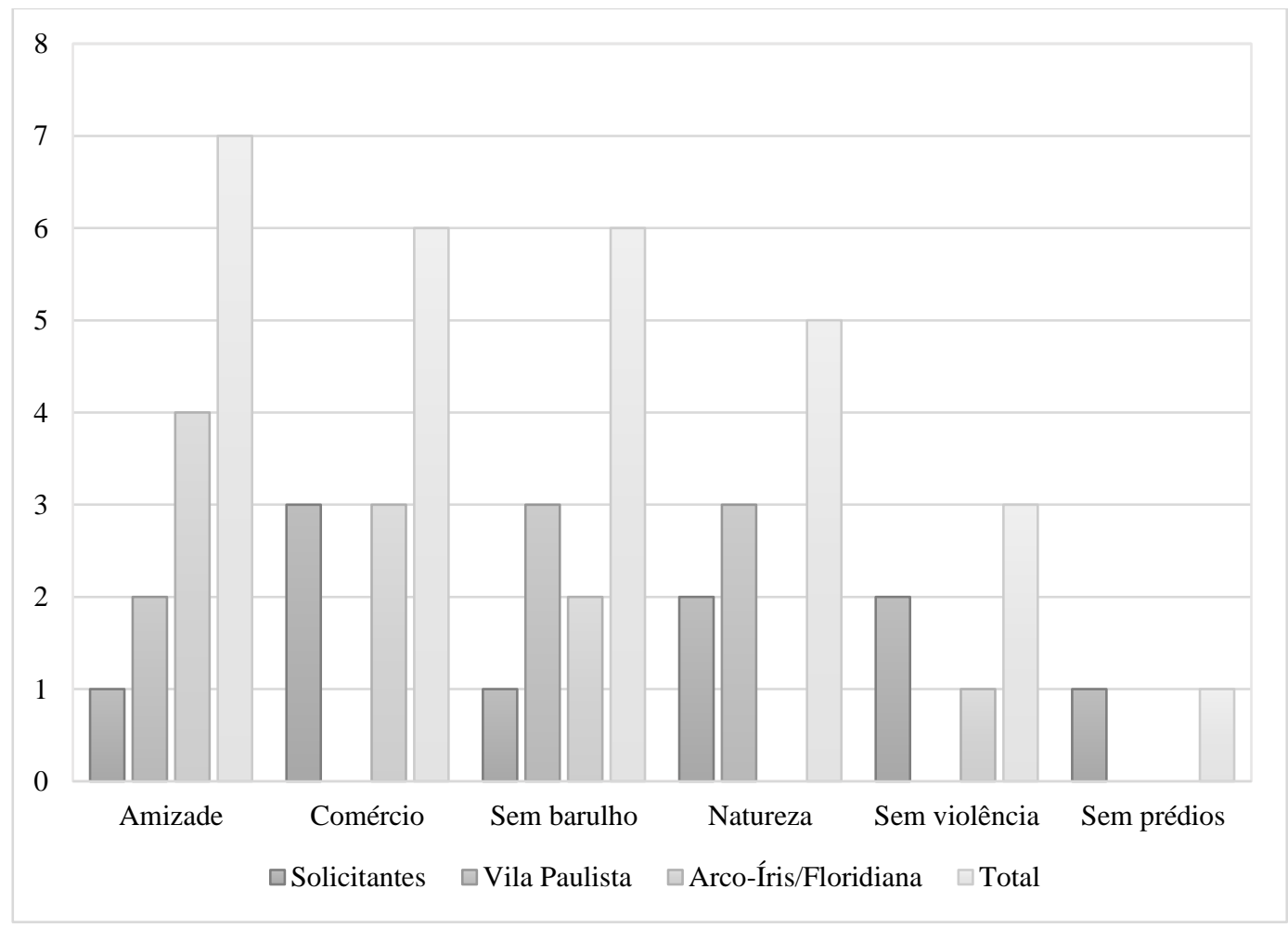

"Natureza" inclui a referência à proximidade com a FEENA no bairro Vila Paulista, arborização nas ruas e presença de praças arborizadas nos outros bairros (Arco Íris/Floridiana, Wenzel, Vila Indaiá, Vila Alemã e Mãe Preta). É significativo identificarmos que ela aparece em $4^{\circ}$ lugar. Mesmo assim, pode-se dizer que ainda é um fator relevante para o bem-estar do munícipe. Salienta-se que este item não foi mencionado no grupo do bairro pouco arborizado (Arco Íris/Floridiana), e foi mencionado por 3 vezes no grupo do bairro bem arborizado (Vila Paulista) e por 2 vezes no grupo dos solicitantes 
de corte. Confirmando novamente, a rica experiência e apreciação de quem mora próxima a uma Área Arborizada e a pouca, no caso nenhuma, importância que os moradores do bairro pouco arborizado (Arco Íris/Floridiana) deram à presença da natureza como fator de boa qualidade de vida, sendo esta atribuída por esse grupo principalmente à amizade em seu bairro.

Figura 5: Número de citações de cada benefício trazido pelas árvores por grupo e total.

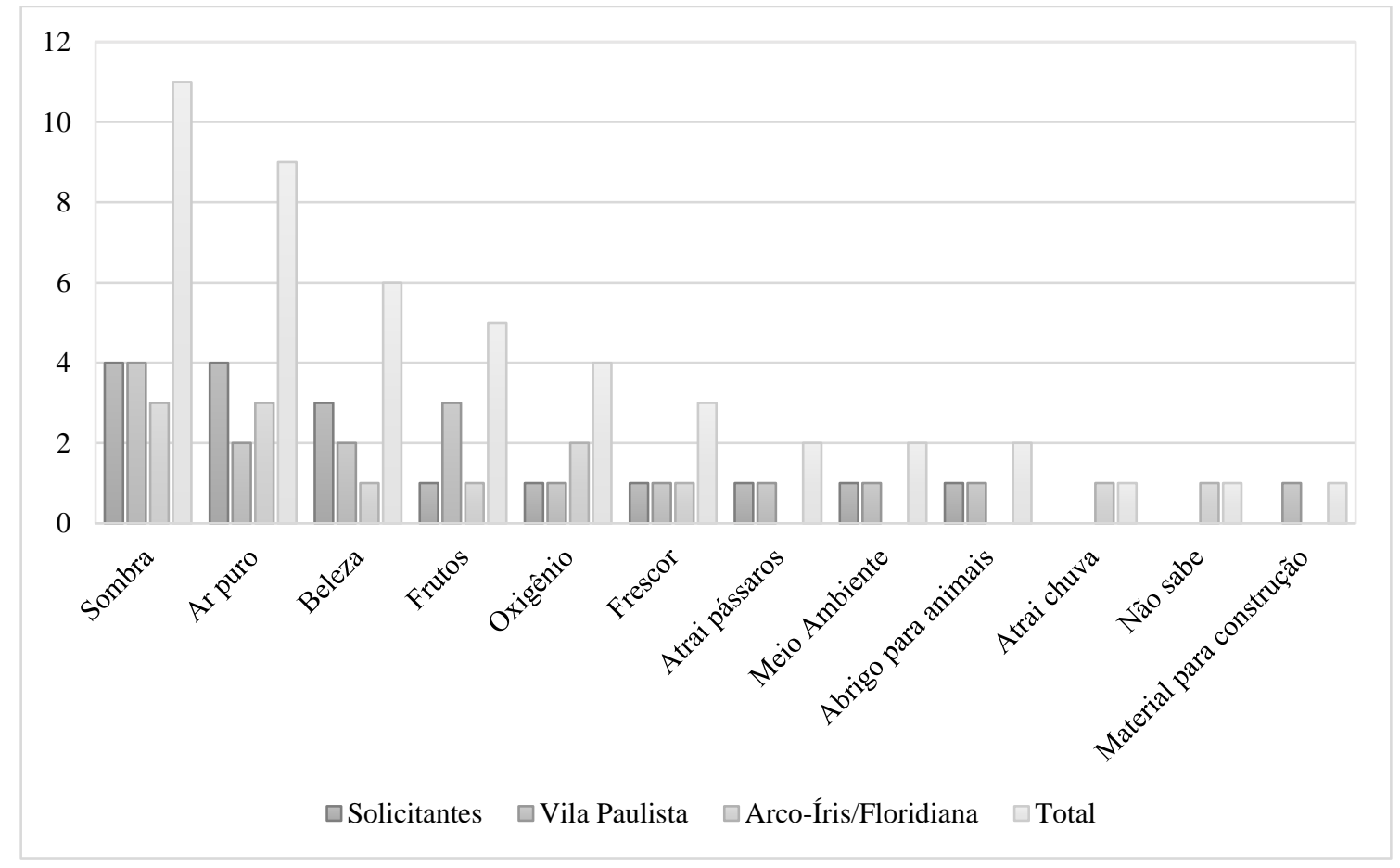

O benefício mais comentado foi a formação de sombras e o de propiciar um ar puro, filtrando a poluição. Isto pode se dever ao fato da cidade de Rio Claro apresentar temperaturas altas e pouca umidade do ar. Ela é considerada uma cidade seca com clima parecido com o semiárido, quente de dia e frio a noite, o que pode nos levar à pergunta sobre qual deve ser a opinião de quem mora em ambientes mais amenos.

Este resultado também foi observado nos estudos das percepções de munícipes de Campinas-SP por Dobbert (2015), o qual apontou que as funções mais recorrentes citadas nas entrevistas foram referentes ao conforto térmico proporcionado pela sombra das árvores, funções relacionadas à melhoria da qualidade do ar. De fato, em ambientes muito quentes, a presença da vegetação garante projeção de sombra que garante sensação de melhor conforto térmico (SARTI, 2009). Em seguida, observamos os prejuízos que as árvores podem trazer para os entrevistados, na figura 6.

Rev. Eletrônica Mestr. Educ. Ambient. Rio Grande, v. 34, n. 3, p. 112-129, set./dez. 2017. 
Figura 6: Prejuízos que as árvores podem causar citados pelos Entrevistados por grupo e total.

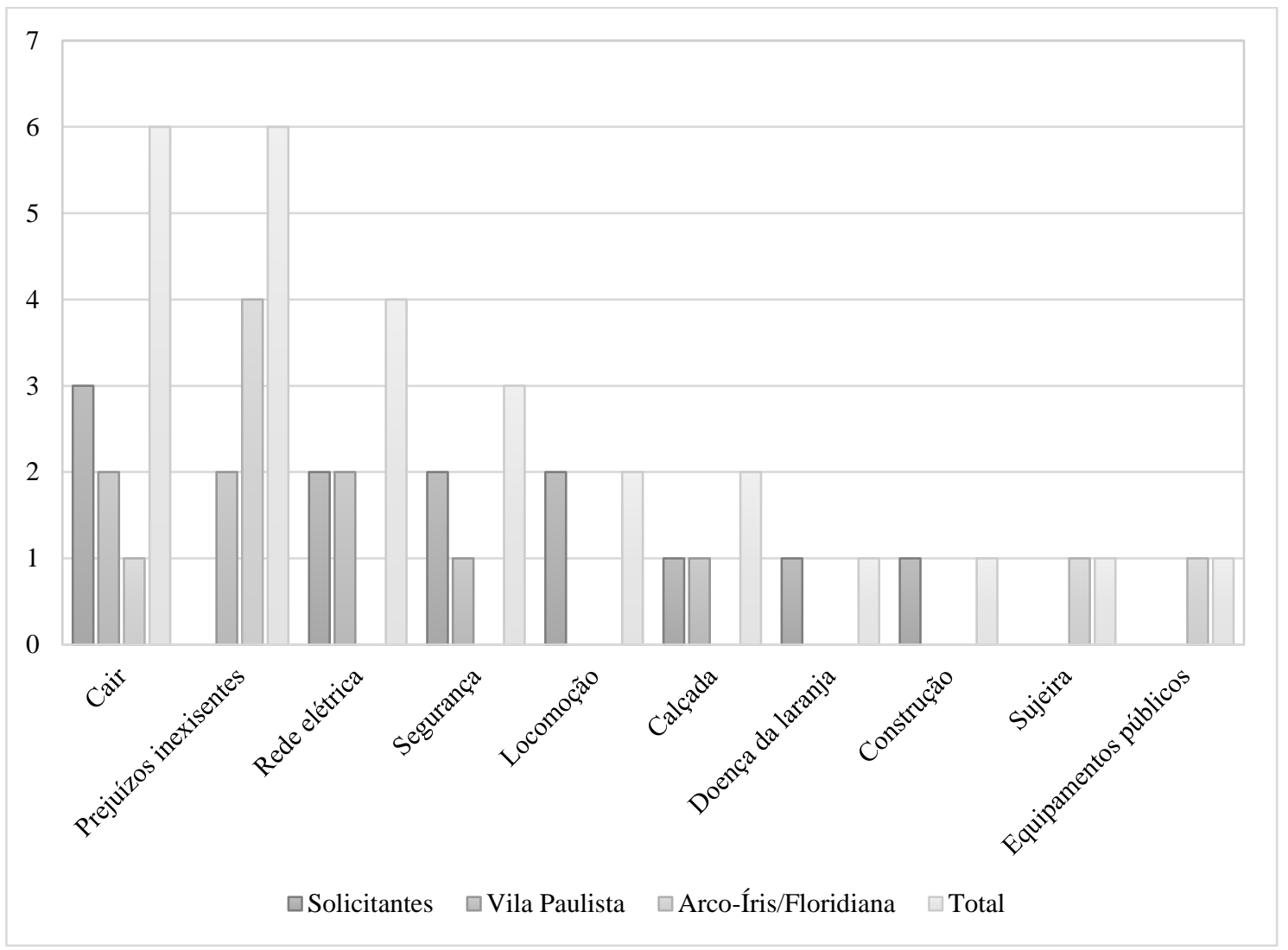

Muitos munícipes, antes de citarem alguns dos empecilhos postos no gráfico, disseram que as árvores não causam problema nenhum, mas depois complementavam com “a não ser que..." e citavam os problemas presentes no gráfico:

"A fiação... Na verdade não são elas [árvores] que causam empecilho, nós é que invadimos os espaços onde elas estavam".

"A não ser nas casas que estejam colocando em risco alguma coisa. Do contrário, acho que não".

"Nenhum problema. Pelo contrário. A minha [solicitação de corte] foi uma necessidade da minha segurança".

"A única coisa que consigo ver é quando plantam em lugares errados".

"Tem hora que soltam muita folhinha e enchem o saco, suja demais, mas faz parte".

"Não tem. Só se ela cair. Se ela cair e alguém estiver passando pode machucar ou até matar. Mas se não cair está "de boa".

Se o município apresentasse rede elétrica subterrânea e estudo urbanístico, planejamento de uma arborização urbana de qualidade, vários problemas citados seriam

Rev. Eletrônica Mestr. Educ. Ambient. Rio Grande, v. 34, n. 3, p. 112-129, set./dez. 2017. 
eliminados, e as árvores não causariam problemas, visto que o risco de cair e causar acidentes também poderiam ser anulados com um bom planejamento arbóreo urbano e informação à população. Dessa forma, permaneceria apenas o empecilho de causar sujeira, mencionado apenas por duas pessoas, representado por $10 \%$ do total; já que "segurança pública”, aspecto que levou a uma solicitação de corte, não está a cargo do setor de planejamento urbano da prefeitura, mas sim a cargo da segurança pública.

É preciso lembrar que a prática do plantio de árvore pelos próprios munícipes não sofre penalização em Rio Claro. Mas, quando ocorre o plantio de espécie inadequada, qualquer pessoa pode solicitar o corte, mesmo que árvore esteja na frente da casa de outro munícipe e este pode não concordar, gerando atrito como foi discutido anteriormente. Entretanto, da mesma forma que a árvore na calçada é de responsabilidade da prefeitura, a calçada em si está sob os cuidados do morador.

Uma solicitação de corte de árvore por estar destruindo a calçada pode ser indeferida pela prefeitura, mas esta não necessita reparar, ou ajudar o dono do domicílio a consertar a calçada. Também quanto ao prejuízo para um munícipe que venha a ocorrer pela queda de indivíduo arbóreo (se, por exemplo, a árvore cair sobre um bem - casa, carro) a prefeitura não tem a responsabilidade de ajudar a arcar com os prejuízos. É considerada uma catástrofe natural, e com isso o município não se responsabiliza.

Estes aspectos são importantes e precisam ser apontados, pois são fatores que interferem na decisão de um munícipe em querer ou não uma árvore em frente à sua casa, já que há mais alternativas que o faça decidir não plantar uma árvore em frente à sua casa do que plantar. Destacamos novamente que o devido planejamento evitaria estes transtornos.

\section{CONSIDERAÇÕES FINAIS}

A partir dos resultados e análises efetuadas, pode-se indicar que os entrevistados apresentaram alguns conhecimentos sobre as árvores e sabem da importância da arborização urbana. A grande maioria, em todos os grupos, declarou que em seu bairro deveria haver mais árvores, aparentemente reconhecendo a importância da arborização urbana.

Foi observado também que a grande maioria apresenta conhecimentos sobre os benefícios e prejuízos que as árvores podem trazer e entendem sua importância dentro da cidade. Entretanto, no discorrer das falas, percebe-se que a maior parte das respostas se baseava em afirmações com caráter utilitarista e antropocêntrico, tão comum em nossa

Rev. Eletrônica Mestr. Educ. Ambient. Rio Grande, v. 34, n. 3, p. 112-129, set./dez. 2017. 
sociedade, resultado da disjunção do homem na natureza. Questiona-se o quanto isto não pode prejudicar nas implementações de programas adequados de arborização urbana, visto que a pessoa com esse olhar apenas se direcionará pelo benefício humano mais imediato dentro de um planejamento urbano, deixando de lado as árvores em si e toda uma relação ecológica da qual participam. Com tal visão imediatista, até mesmo os problemas mais visíveis como alta temperatura e falta de escoamento de água urbana são desconsiderados.

Esta perspectiva tão presente em nossa sociedade atual deve ser superada, já que está trazendo muitos prejuízos à dinâmica dos processos naturais, e que acabam afetando também nossa saúde. Como indicado nesta pesquisa, uma proposta de Educação Ambiental sob a abordagem apresentada nesse trabalho ajudaria a ultrapassar essa perspectiva, colaborando na busca por um ambiente urbano mais equilibrado, com cidadãos participativos, conscientes e responsáveis por ações mais adequadas.

A EA pode ajudar para que o reconhecimento da importância das árvores seja ampliado, não só sob uma forma utilitarista, mas envolvendo conhecimentos, valores e ações mais apropriadas como, por exemplo, a do sujeito que mudou a entrada do carro em sua casa e não precisou cortar a árvore que inicialmente cortaria.

Sempre é tempo de se educar para uma valorização menos utilitarista das árvores e a EA pode ser direcionada a esse objetivo, voltando-se a pessoas de qualquer idade, dentro ou fora das escolas, de forma a contribuir para uma relação mais saudável e consciente entre sociedade-sociedade e sociedade- natureza.

\section{REFERÊNCIAS}

CADORIN, D. A. A Arborização Viária no Município De Pato Branco - PR e suas relações com solos urbanos e percepção dos moradores. 2013. 155f. Dissertação (Mestrado em Desenvolvimento Regional) - Programa de Pós-Graduação em Desenvolvimento Regional, Universidade Tecnológica Federal Do Paraná, Pato Branco, 2013.

CARVALHO, I. C. M. Educação ambiental: a formação do sujeito ecológico. São Paulo: Cortez, 2008.

CARVALHO, L. M. Educação e meio ambiente na escola fundamental: perspectivas e possibilidades. Projeto-Revista de educação, Porto Alegre, v. 1, n.1, p. 35-39, 1999.

DOBBERT, L. Y. Arborização na cidade de Campinas/SP- percepção e conforto. 2015. 186 f. Tese (Doutorado em Ciências) - Escola Superior de Agricultura "Luiz de Queiroz", Universidade de São Paulo, Piracicaba, 2015.

IBGE. Cidades. Disponível em:<https://cidades.ibge.gov.br/brasil/sp/rioclaro/panorama>.Acesso em: 15 mai. 2015. 
LAYRARGUES, P. P. Identidades da educação ambiental brasileira. Brasília: Ministério do Meio Ambiente, p. 65- 83, 2004. Disponível em:< http://www.mma.gov.br/estruturas/educamb/_arquivos/livro_ieab.pdf >. Acesso em: 15 mai. 2015.

LUDKE, M; ANDRÉ, M. E. D. A. Pesquisa em educação: abordagens qualitativas. São Paulo: EPU, 1986.

BRASIL. Ministério da Educação. Educação Ambiental no Brasil. Brasília, DF, 2008, 54p. Disponível em:< http://forumeja.org.br/sites/forumeja.org.br/files/Educa\%C3\%A7\%C3\%A3o\%20Ambienta 1\%20no\%20Brasil\%20(texto\%20basico).pdf>. Acesso em: 12 nov. 2017.

MONICO, I M. Avaliação e arborização na cidade de Piracicaba - SP um olhar sobre a questão à luz da educação ambiental. 2001. 165 f. Dissertação (Mestrado em Ciências Florestais) - Escola Superior de Agricultura "Luiz de Queiroz", Universidade de São Paulo, Piracicaba, 2001.

MOURA, I. R. Arborização urbana: Estudo das praças do bairro centro de Teresina. 2010. 127f. Dissertação (Mestrado em Geografia) - Instituto de Geociências e Ciências Exatas, Universidade Estadual Paulista "Júlio de Mesquita Filho", Rio Claro, 2010.

NARCIZO, K. R. S. Uma análise sobre a importância de trabalhar educação ambiental nas escolas. Revista eletrônica do mestrado em educação ambiental. Rio Grande: FURG, v. 22, jan/jul. 2009. Disponível em:<http://www.seer.furg.br/remea/article/view/2807/1583>. Acesso em: 15 mai. 2015.

SANTOS, A. G; SANTO, C. A. P. Inserção da Educação Ambiental no Currículo Escolar. Revista Monografias Ambientais -REMOA, v. 15, n. 1, p. 369-380, jan/abr. 2016.

SARTI, A. C. Floresta urbana: propostas de gestão e subsídios para políticas públicas em Rio Claro (SP). 2009. 179 f. Tese. (Doutorado em Geografia). - Programa de PósGraduação em Geografia, Universidade Estadual Paulista "Júlio de Mesquita Filho", Rio Claro, 2009.

VALENTIN, L. Projetos de educação ambiental no contexto escolar: concepções e práticas. 2005. 175f. Dissertação (Mestrado em Educação) Universidade Estadual Paulista "Júlio de Mesquita Filho", Rio Claro, 2005.

Submetido em: 13-07-2017.

Publicado em: 15-12-2017.

Rev. Eletrônica Mestr. Educ. Ambient. Rio Grande, v. 34, n. 3, p. 112-129, set./dez. 2017. 